\title{
Some Useful Equipment in the Rehabilitation of Permanent Spinal Paraplegics.
}

\author{
By ALFRED ROTHBERG \\ Superintendent Physiotherapist, Rehabilitation Centre, W.N.L.A.-Hospital, Johannesburg.
}

\section{(I.) A BALANCING AID.}

THE physical rehabilitation of permanent spinal paraplegics has to-day become an established item in the programme of adequately equipped Rehabilitation centres. li has become possible to teach them crutch walking with the aid of long corsettype calipers. Provided no untoward complications occur, this programme usually takes four to six months.

Occasionally, however, the physiotherapist entrusted with the re-anbulation of spinal paraplegics encounters a patient who is not progressing according to schedule. A patient who started very promisingly, seems to approach a standstill in his progress.

Sometimes it is a patient with a cauda equina lesion and resultant flaccid paralysis of his legs who has done very well during every stage of pre-ambulation exercises. He has developed an adequate shoulder girdle and strong arm and hand muscles. His back and abdominal muscles have been built up. He is even walking well with his calipers in the wheel-crutch. Yet when he changes to ordinary crutches he becomes disappointingly slow. He lacks just that little extra confidence which would give him that easy lift for the swing-through movement, that well extended back and braced shoulders before advancing the crutches, and that steady shifting of weight from side to side, all of which make the crutch-walking of some paraplegics, considering their grave disability, appear almost graceful.

Another type of flaccid paraplegic may be handicapped by genuinely weak back and abdominal muscles. In the wheelcrutch we find him resting heavily on the axillary pads, almost hanging between the uprights. He resents extension of his back, tends to drag his legs, and is not easily persuaded to use his strong arms to lift himself towards the straight position.

If given ordinary crutches he would either sag forward or try to maintain himself standing with his spine flexed at a marked angle. In either position he would appear glued to the ground and convinced that it was impossible for him to propel himself forward.

In the category of spastic paraplegics there is a fairly frequent type of mid-thoracic cord lesion, in which the patient eventually masters his abdominal spasm sufficiently to assume the erect position in the walking machine, and with the aid of calipers learns to propel himself in it. However, when promoted to crutches, his former control of spasticity seems lost. Adopting a posture of acute flexion at the hips, he can just maintain himself between the crutches. Every effort at relaxing his tense abdominals produces only a reflex action returning hin to the initial flexed position.

All these types, with constant tuition, will eventually learn the art of crutch walking. Gradually their confidence will increase. They will trust a muscle even if it is somewhat below normal strength, and they will lose the apprehension of an impending fall. But whenever the rehabilitation therapist meets one of these difficult patients, much additional time will have to be devoted to such a patient. guiding hin towards better balance.

A flaccid paralysis case once described to me his difficulty in balancing with calipers and crutches. He said his trunk felt like a sharpened pencil trying to stand with its point on a polished table. And, pointing to his pelvis, he added that the table was not steady either.

With this picture in mind it seemed worth trying whether stabilizıng the "table" would facilitate and speed up the acquisition of balance in the erect position.

The simplest way appeared to be a fixation of the walking calipers to the ground. The patient could thus be freed from fear of falling and concentrate on the balance of his upper body.

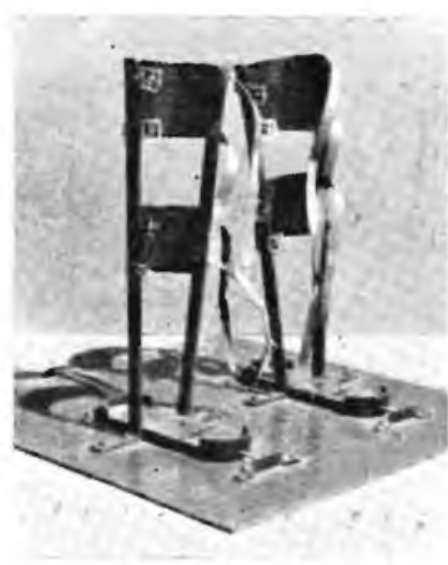

FIG. 1 .

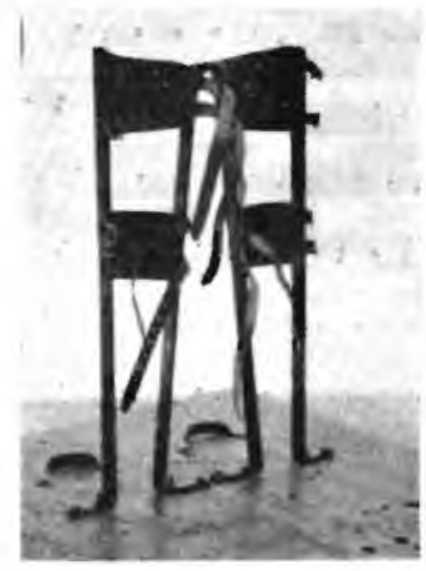

FIG. 2 .

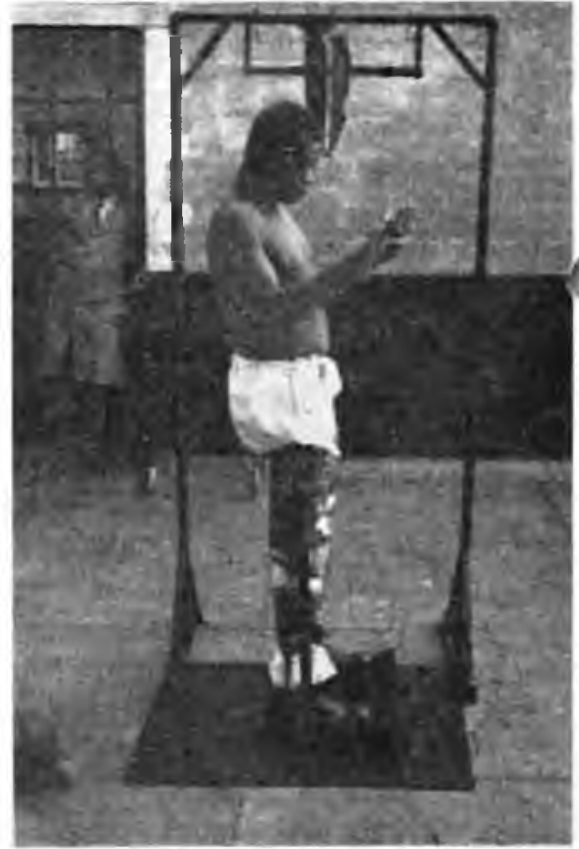

FIG. 3 . 


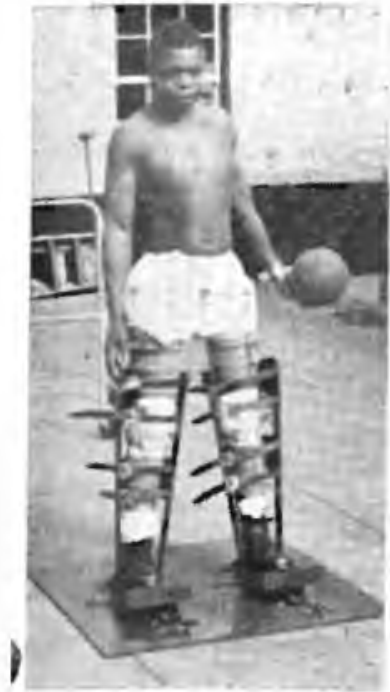

FIG. 4 .

Figures I and 2 show the type of double leg brace which our works department assembled as a portable unit on a sturdy steel plate. It is so constructed that it comfortably anchors the patient in his walking calipers to the base-plate and straps him securely to the semicylindrical leg supports.

The success of this apparatus was gratifying. The very patient for whom I had designed it turned from a disinterested near-objector to an ardent collaborator who simply could not get enough of his daily work-out in the "Balancer." At first still hanging on with one hand to an overhead strap, he soon balanced without holding on, learned to swing back to good hyperextension and forward beyond the vertical. After only a couple of days he himself asked for his crutches which until then he had loathed. To lift the crutches alternately for a three-point support ceased to be a terrifying experience for him. Shifting of the body weight from side to side became easy, and within another few days he was independent with his crutches.

It was obvious that in his case weeks of arduous work had been saved. Since then many of our patients have quickly gained confidence through this simple appliance.

Fig. 3 shows a patient with a fracture of the lumbar spine and resultant flaccid paraplegia securely braced in the apparatus. He is concentrating on maintaining the erect position just after he has released his grip on the overhead strap next to him.

We did not limit the application of the apparatus to plain balancing exercises. In order to encourage a wider range of movement, develop increasing confidence, and provide an incentive to longer practice periods, we branched out into the field of play and games in the upright position.

We introduced catching and throwing of tennis balls, leading to aiming at targets and throwing the ball through hoops.

The fairly substantial 8 -inch rubber ball provided the next step in the progression (Fig. 4). Throwing it over high bars and into net-ball baskets added range and accuracy to the body swing.

Attached to a rope it was used as a slow punching ball (Fig. 5).

A few patients developed sufficient control and co-ordination to let them try their hand at dart throwing.

To encourage swift and sweeping arm movements we gave our patients table-tennis bats and showed them how to hit the pingpong ball (Fig. 6).

This proved such an

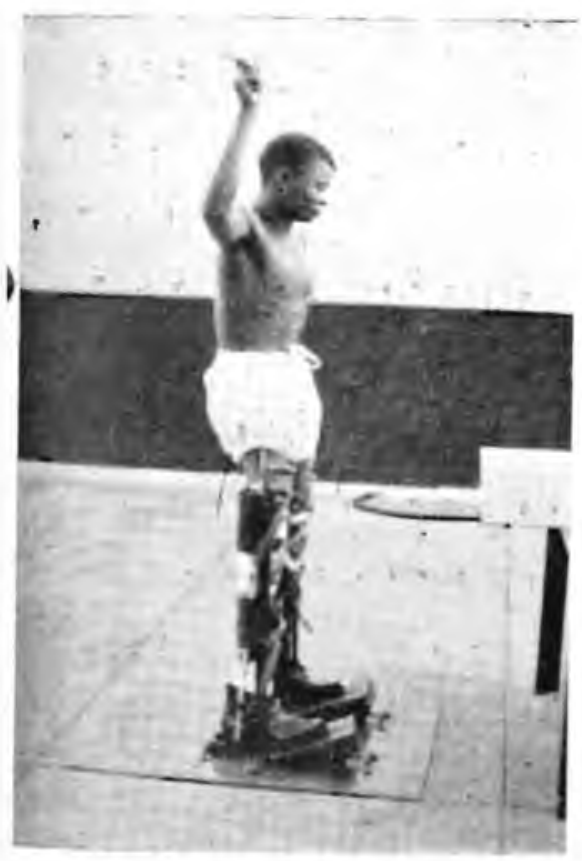

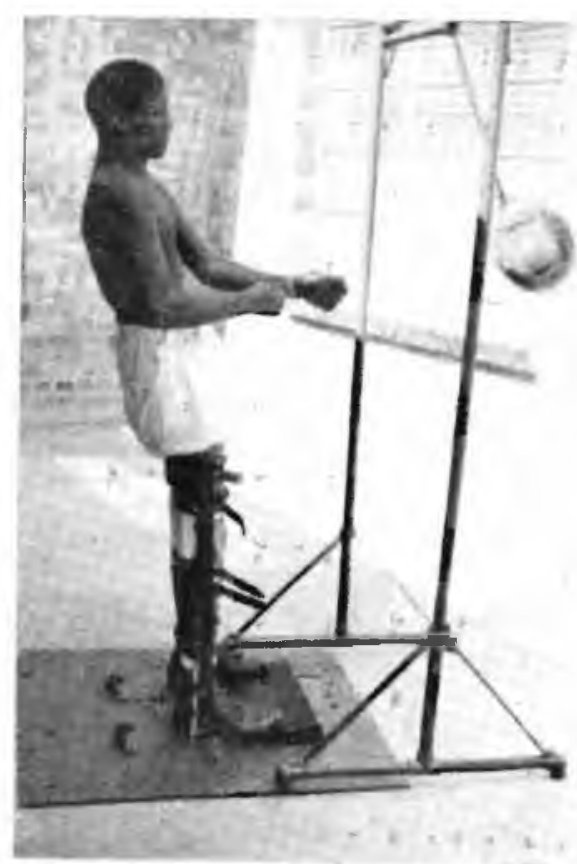

FIG. 5 . attraction that we rigged up an improvised ping-pong

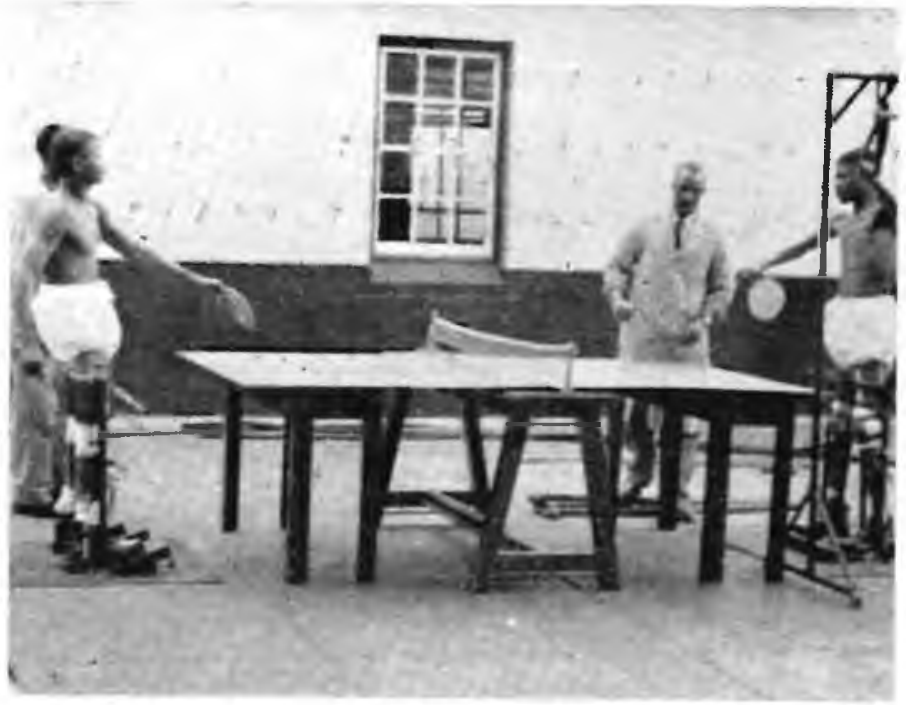

FIG. 6 .

FIG. 7 . 


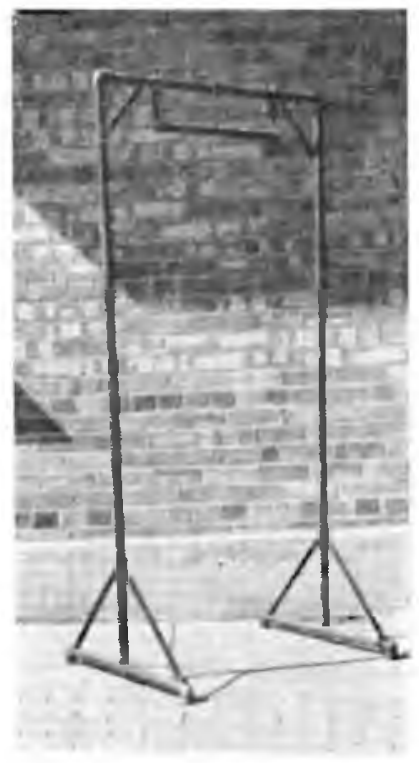

FIG. 8

table. Before long we organsed the first "match" betwcen two complete paraplegics supported in the leg-stabilizer. Figure 7 shows a set between an expert and a beginner. the latter still holding on to an overhead strap.

All these activities compensated us to some extent for out inability to introduce on an adequate scale the much admired wheel-chair sports and ganes developed by Dr. Guttmann of Stoke-Mandeville, for which, unfortunately, our centre-of-city hosptal has neither anple grounds nor facilities.

Other uses of the apparatus can be found in the rehabilitation of badly affected polio- . patients. A suttably adapted smaller machme helped a badly paralysed polio-child of four years on to calipers and crutches, and a little boy suffering fiom cerebral palsy built up confidence to overcome eventually his tendency to fall to the ground. Both children enjoyed exercise and play with their legs firmly secured. In these cases again much time was saved.

In the Occupational Therapy Department the apparatus may be helpful to let patients castry out such widerange movements as wood planing and sauing. The portability of the apparatus should increase tts usefulness.

\section{(II.) PORTABLE} OVERHEAD

FRAMIE. (Fig. 8). This frame was designed at an early stage of our work with spinal paraplegics. At that time, now several years ago, we sometimes recelved at our Centre patients with fractured spines, who had already spent a long period in their local hospitals, and had developed lange pressure sores on back and hips. A treatment programme for these sores was worked out in great detail in conjunction with the nursing staff In this careful routine it was an important point to avoid friction and irritation of the affected areas when moving the patient from the ward to the rehabilitation department, and when helping him from the lying to the standing position for his walking exercises.

The overhead frame reduced the risk of such friction to a mininum. It is wide enough to allow a wheelstretcher or even a hospital bed on wheels to fit between the upright poles

The transfer from the lying to the standing position

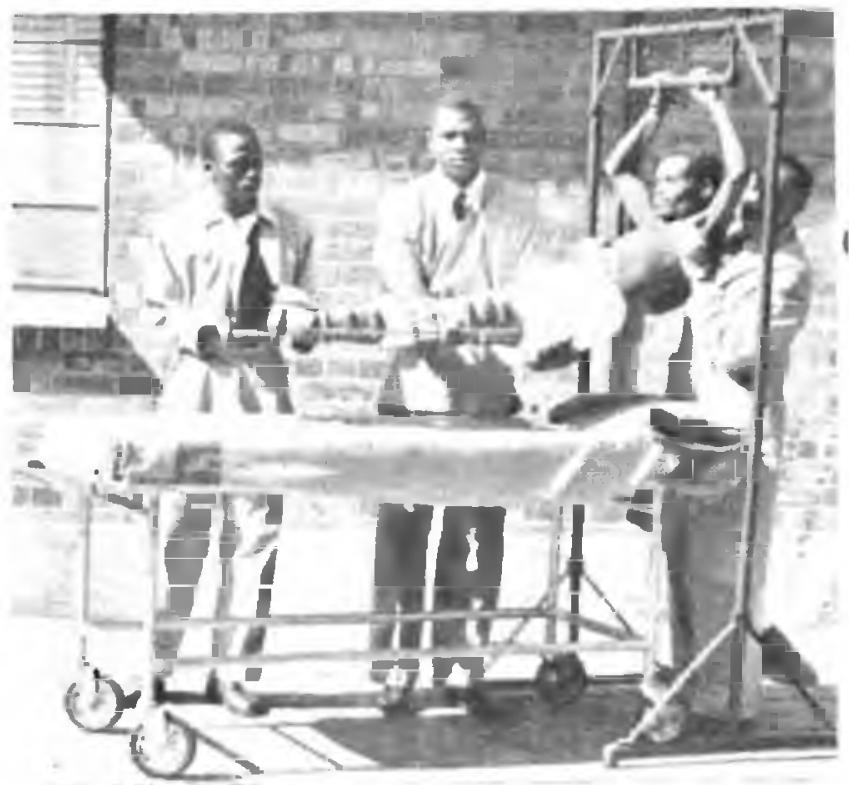

FIG. 9. is divided into five stages:

(I) The patient, ready with calipers and boots. Iies flat on the stretcher. The head end of the stretcher is wheeled under the cross-bar of the frame.

(11) He is assisted at the shoulders so that he can grasp the bar with arms extended.

(ii) Pulling himself up with bent elbows he is lifted clear off the stretcher (Fig. 9).

(iv) The stretcher is slipped out.

(v) The patient, still holding on to the bar, is gently lowered to the standing position. (Fig, 10).

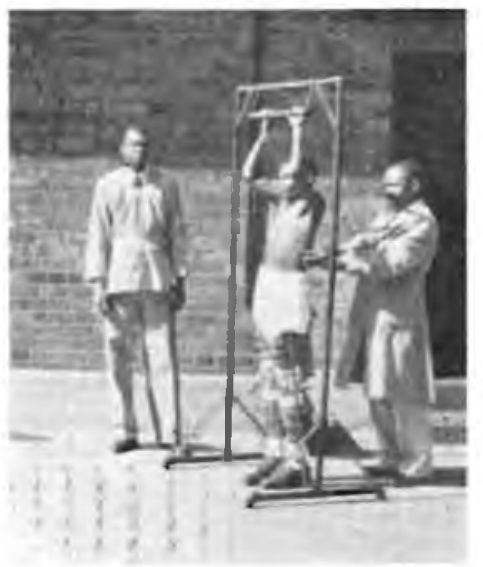

FIG. 10 .

According to the stage of the pattent's progress either the axillary pads of the wheel-crutch (walking machine) or his ordinary crutches are then placed right under his armpits. He changes his grip from the horizontal bar of the frame to the cruich handles, and is ready to commence standing and walkıng exercises.

At the end of these exercises, the lifting routine is reversed

The patient finishes his walking exercises immediately under the frame. He releases his grip on the crutch handles, changes to a firm grip on the horizontal bar of the frame, pulls himself up and is lifted to the horizontal position. The stretcher or bed is then wheeled under, and the patient is gently lowered on to it.

Pressure sores, fortunately, no longer constitute a problem. Great strides have been made in their prevention, and patients with fractured spines are sent at an early stage to the Rehabilitation Centre.

But the routine of getting the patient from the lying to the standing position with the aid of the overhead frame we have retanned. It has proved a safe, time-saving and, above all, satisfactory method to the patient who feels that he hiniself takes a very active part in it.

On warm days the frame is taken to the court-yard and the patient goes through his routine in the open air.

In the wards we have used the portable frame for various other purposes. Easily sliding over the beds, it is often employed when pernanent overhead frames or Balkan frames are not immediately available or otherwise not indicated. Slings can easily 
be hooked on to the cross-bar of the frame, allowing elevation of a limb or exercises in sling-suspension. With rope handles attached to the cross-bar. the frame provides purchase for early pullıng-up exercises towalds the sitting position. Steel bar's with iron discs can be securely suspended above the patıent's head, supplying hım with weightlifting equipment for shoulder ,arm, and elbow exercises against resistance whilst lyıng on his back.

\section{(III.) IMPROVISED SUSPENSION SLINGS}

The importance of suspension exercises in rehabilitation work is well known. Many physiotherapy departments are equpped with proper Guthrie-Smith Suspension Apparatus. There are, however, still hospitals without this valuable equipment.

Dunng the war years, when proper Guthrie-Smith apparatus was hardly obtainable in this country, we employed various improvisations.

A simple yel quite efficient substitute was found in the application of bicycle tyres of balloon size $26 \% 2$, which provide both support and elasticity.

Suspended from Balkan frames, swan necks (monkey chain holders), or similar overhead supports, these improvised slings enabled us to give a good deal of suspension therapy to our patients.

Although this is only an improvisation and fat from the versatility of the genume equipment, it is described here, because many visiting medical officers and physiotherapists were impressed by its simplicity and easy application.

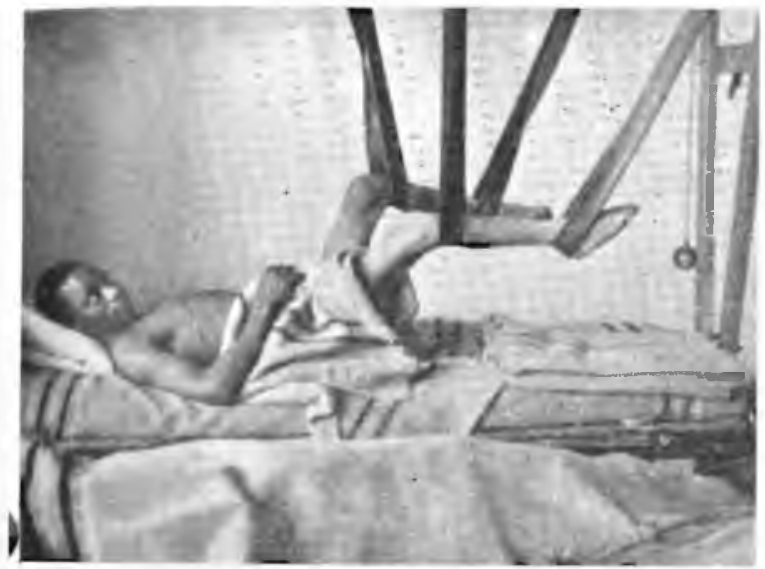

FIG. 11 .

Figure 11 shows a spastic paraplegic with flexion deformities at hıps and knees comfortably slung up while concentiating on relaxation exercises.

\section{SUMMARY.}

Three types of equipment are desclibed and illusurated:

(1) A Trunk Balance Aid in the form of double leg braces, securing the patjent to the ground in the standing position.

(2) A Portable Overhead Frame which has been found useful in transferring the patient speedily and safely from the lying to the standing position. Other uses of the frame, especially in the ward, are also described.

(3) Improvised Suspension Slings in the shape of bicycle tubes, as a stand-by in hospitals where proper suspension apparatus is not available.

\section{PERSONAL}

Miss Jean Blair left by plane on June Ist for London where she will spend a holiday. She will be back at the beginning of August

Miss Guen Wilson, physiotherapy lecturer on the staff of the University of the Witwatersiand, was matried recently to $\mathrm{Mr}$. K. Taylor:

Mrs. C. Levy (nee Sack) gave birth to a son on May Ist.

Mr. A. A. Wcil has left the stafi of Baragwanath Hospital and is now in private practice.

Mis. J. Bratredt has left to go overseas for an indefinite period. She has been given leave of absence from the Central Executive Committee and her place as Secretary; Treasurer of the Southern Transwaal Branch has been filled jointly by Miss Sandra Saber and Miss Carol Baker.

The Johannesburg General Hospital welcones to its staff Mrs. Wendy Blowne (nee Eybers), who has returned from England where she gained experience particularly in chest work at Harefield.

Mrs. Eilcen Gumter is doing valuable work for the Hospital as a remedial gymnast.

We are sorry to lose from the staff Miss Jean ScottRussell who has gonc to the Frese Hospital, East London, and Mrs. D. Courlander who has moved to Southern Rhodesia.

\section{CHANGES OF ADDRESS}

Mr. J. G. Koehorst to 608 , U.B.S. Buildings, Bloemfonteın.

Miss E. Kamptner to 6, Cordelvos Crescent, Iscor Township, Pretoria.

Miss U. Moflit to Physiorherapy Dept., Baragwanath Hospital, Johannesburg

Mrs. E. B. Searcey to 13, Truborough Mansions, North Street, Illovo, Johannesburg.

Mr. A. R. W. Gabriel to c/o Umlamli Hospital, P.O. Sterkspruit, Helschel District, Cape Province.

Mr. P. A. C. Kelly and Mr. L. G. Holton to 287a, Skinner Street, Pretoria.

Mrs. G. Browne (nee Eybers) to 7 Tressry Place, Simmer Street, Germiston.

Mrs. L. L. Channock to 468, Musgrave Road, Durban.

Mrs. E. A. Cotter to Medical Centre, 23 Joubert Street, Vereenıging.

Mrs. G. Dell (nee Andrews) to 2. Mimosa Court, 342, Louis Botha Avenue, Orange Grove, Johannesburg.

Mrs. L. Levy (nce Loon) to 48, Wesibury Road, Belleville, Cape.

Mrs. S. Lcwis (nee Robinson) to 4, Alexia Court, 3rd Avenue, Peacehaven, Vereeniging.

Mrs. H. M. Sanders to Evelyn House, 114, High Street, Grahamstown, Cape Province.

Mrs. Uniacke to 23, The Drive, Durban North.

Mrs. M. Becker to Box 143, P.O. Westville, Natal.

Mrs. D. Courlander to P.O. Box 148, Bulawayo, Southern Rhodesia. 